\title{
Authenticity and Teacher's Role in Project Based Learning
}

\author{
Lusine Madoyan \\ Yerevan State University
}

\begin{abstract}
Project based learning (PBL) is a student-centered teaching method that involves a dynamic classroom approach in which students gain knowledge and skills to explore and respond to an authentic and engaging problem or challenge. PBL focuses on different real-world subject matters that can sustain the interest of students, require student collaboration and autonomy, and at the same time, accommodate a purposeful and explicit focus on form and other aspects of language.

The present article focuses on the teacher's role in project based learning as well as the importance of authenticity in designing a project.
\end{abstract}

Key words: project based learning, authentic materials, motivation, EFL, teacher's role, real-life skills.

\section{Introduction}

Project based learning is widely viewed as a valuable pedagogical approach allowing teachers to target material that motivates students and giving learners the freedom to explore and learn about topics that interest them. It encourages learners to be at the center of the process and promotes autonomy, problem-solving, critical thinking, as well as interpersonal and life skills.

PBL also helps motivate students to learn language for a specific purpose and promotes community among class members by creating an atmosphere of cooperation and team-work.

In PBL, the students are presented with authentic problems before they receive instruction. They then must learn the content and skills necessary for solving the problem through collaborative research, discussion, and strategic planning. Content learning and skills occur as natural consequences of solving problems, similar to the way people learn on the job (Gaer 1998).

The implementation of project work differs greatly from one instructional setting to another. In some settings, fairly non-elaborated tasks, confined to a single class session, are labeled as projects. In other settings, elaborate sets of tasks establish the process for completing the project and span an entire instructional 
unit; in settings like these, the benefits of project work are maximized because students are actively engaged in information gathering, processing, and reporting over a period of time, and the outcome is increased content knowledge and language mastery.

\section{Teacher's Role in PBL}

Ideally, it is the students who choose projects, but since in lower-level classes students often do not have the required language skills or confidence to develop project themes, the teacher must listen to them and try to identify some underlying issues that are meaningful to the students, paying special attention to their needs, interests, cultural background, jobs, etc.

With beginner level students, the teacher may have to take a fairly active role, providing examples of previously completed projects to encourage the students to produce their own. With more advanced classes, however, it is easier to get the class to develop a project that meets a need they have identified. In these situations, the teacher takes the role of a facilitator (Gaer 1998).

Projects that students choose to do may be based on some topic in their textbook or may merely be a source of entertainment and a break from routine classroom activities.

As Wentzel and Brophy (2014) state, student motivation should be at the center of project design as the students must see value in a project in order to be willing to enroll in it.

When outlining a project, teachers must always keep in mind the linguistic objectives and the content standards that will be addressed. The choice of the topic is also of huge importance, it must be up-to-date, motivate the students and keep them interested throughout the project. It is important to involve the students in planning and decision making since this will help them develop a feeling of ownership of the project. After agreeing on the theme of the project and determining the final outcome of the project (e.g., written report, brochure, handbook, oral presentation, video, multimedia presentation, theatrical performance), the teacher must also design a timeline for project components and help the students define a specific flexible schedule to accomplish the project.

The teacher's initial role in PBL is to develop realistic and authentic problems and materials, and as soon as this task has been fulfilled, the teacher fades into the background while students engage in solving the problem. 
The students take on the role of whatever person is solving the problem, generate a list of learning issues and whenever a new learning issue arises, the students must create an action plan to tackle this issue.

The teacher can help by directing the students to information which will answer their questions, but should not answer the questions per se. Students must regard the teacher as a guide so the teacher should not try to control everything and must leave some autonomy to the students. Finding the proper balance between teacher guidance and student autonomy enhances the advantages of project work in the language classroom.

The teacher designs language-improvement activities to help students successfully present the final outcome of the project. Those activities may focus on skills for successful oral presentations, persuasive debates, editing, and so forth.

After engaging in teacher-guided preparatory activities, students start to compile and analyze the gathered data. They work in groups to organize the information and then discuss the value of the data that they have collected, keeping some and discarding others.

Another role of the teacher is to monitor the students and the progress of the project, as well as to assess the final outcome. The teacher should not forget to ask the students to provide feedback on the project experience and to reflect on the language and the subject matter acquired during the project. This will help the teacher see the drawbacks of the project and make it more elaborate each year. In this last stage of project work teachers also provide students with feedback on their language and content learning.

One of the most important things the teacher should not forget when using project based learning is to ask the students to provide feedback on the project experience. This will help the teacher see the drawbacks of the project and make it more elaborate each year.

\section{Authenticity of a Project}

Many specialists refer to Morrow (1977:13) for their definition of authenticity: "An authentic text is a stretch of real language, produced and designed to convey a real message of some sort". According to Harmer (1983:146) "authentic texts (either written or spoken) are those which are designed for native speakers: they are real texts designed not for language students, but for the speakers of the language in question". 
This is a good place to start, but falls short when we attempt to define authenticity in regard to PBL. In order to define authenticity in PBL, we must take into consideration the various aspects of authenticity, such as the initial input and final output, the participants, the setting, the nature of the interaction, etc. Thus, when speaking about the authenticity of a project, we should bear in mind that the materials and the sources that the students use must be authentic (examples of authentic input commonly employed are films, commercials, texts from print media, audio recordings and many other types). Moreover, the task itself, the output and the audience must ideally also be authentic. The authenticity of the above mentioned features may improve the benefit of PBL for learners and instructors and as Stoller (2006) emphasizes, the most commonly cited benefit of PBL is the authenticity of experience and language.

J. Larmer (2012) defines the following four authenticity criteria for a project:

1. The project meets a real need in the world beyond the classroom, or the products that students create are used by real people.

2. The project focuses on a problem, issue or topic that is relevant to students' lives, or on a problem or issue that is actually being faced by adults in the world students will soon enter.

3. The project sets up a scenario or simulation that is realistic, even if it is fictitious.

4. The project involves tools, tasks or processes used by adults in real settings and by professionals in the workplace.

This focus of context with real-world themes or issues provides the authenticity that teachers strive for, and learners often appreciate. Stoller (2006) states that the vast majority of project work exposes learners to the target language through the use of authentic information sources. However, it is questionable whether this is sufficient to motivate learners to communicate in the target language throughout the project cycle. In many cases the authenticity and the use of the target language is limited to the initial stage of the project cycle where the students only collect information data to obtain the background content they need to complete the project. During some other stages of the project, the students may opt to use their native language when assigned to work in groups or individually at home without the teacher being able to monitor the process.

The tasks that the teacher assigns the students to carry out for the project must also be authentic. By an authentic task, we mean those tasks which enable learners to use the knowledge they have gained in the classroom to solve real-life problems. 
Authentic tasks create a bridge between what is learned in the classroom and why this knowledge is important to the world outside of the classroom. An important aspect of task authenticity is the degree of real communication that takes place while working on the project. To fulfill this aspect, we need authentic audience since when students submit project work to peers, they are likely to believe their peers will forgive them for gaps in their knowledge of content or the target language. Learners are usually motivated to work harder when their work has an authentic audience. Also, ideally learners will be able to receive authentic feedback from the audience, which may also be quite motivating.

An example of a good project with a high degree of authenticity can be designing a website for a tourist information agency. In regard to input for this project, the learners can visit websites or travel agents and gather the necessary information. With the advent of Skype and free telecommunication learners can actually call hotels and ask for availability and prices for a variety of rooms. To complete the project and develop the final product the students will have to accomplish different authentic tasks such as determining the most economical airfare, hotels, meals package, and car rental. Learners can also be tasked to design a plan for sight-seeing, draw up sketches of the website and develop content for the site.

\section{Conclusion}

In conclusion we may say that PBL is a very good technique of teaching English for Specific Purposes as it can provide the students with the relevant linguistic and professional skills to accomplish different work-related tasks. It becomes a real life experience and will definitely help the learners in their future jobs.

The end result is often authenticity of experience, improved language and content knowledge, increased metacognitive awareness, enhanced critical thinking and decision-making abilities, intensity of motivation and engagement, improved social skills, and a familiarity with target language resources.

PBL helps students learn skills and strategies in addition to content. Students take on the positions of executives, producers, designers, planners, scientists, doctors, historians, and so on and find themselves learning research skills, time management, self-directed learning, transferring knowledge, and other lifelong learning skills while finding information to solve the problem.

Another advantage of using PBL in ESL/EFL classrooms is that your students will have more control over the actual vocabulary they learn, because they must determine what vocabulary they need to know. 


\section{References:}

1. Bülent, A. and Stoller, F.L. (2005) Maximizing the Benefits of Project Work in Foreign Language Classrooms. // English Teaching Forum, Vol. 43 (4).

2. Gaer, S. (1998) Less Teaching and More Learning. Vol. 2. Available at $<\mathrm{http}$ ://www.ncsall.net/index.html@id=385.html> [Accessed May 2015].

3. Harmer, J. (1991) The Practice of English Language Teaching. New edition, London: Longman.

4. Larmer, J. What Does It Take for a Project to Be "Authentic"? Available at: $<$ https://www.edutopia.org/blog/authentic-project-based-learning-john-larmer> [Accessed October 2016].

5. Morrow, K. (1977) Authentic Texts in ESP. // English for Specific Purposes. / Ed. by S. Holden. London: Modern English Publications.

6. Stoller, F. (2006) Establishing a Theoretical Foundation for Project-Based Learning in Second and Foreign Language Contexts. // Project-Based Second and Foreign Language Education: Past, Present, and Future. / Ed. by G. H. Beckett \& P. C. Miller. Greenwich: Information Age Publishing.

7. Wentzel, K.R. \& Brophy, J.E. (2014) Motivating Students to Learn. New York \& London.

8. Wilkerson, L. and Feletti, G. (1989) Problem-Based Learning: One Approach to Increasing Student Participation. // New Directions for Teaching and Learning, I. N. 37 pp. 51-60.

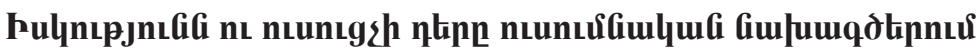

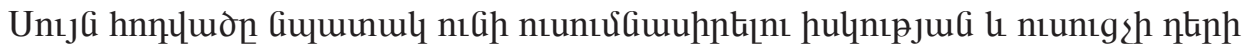

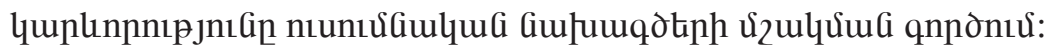

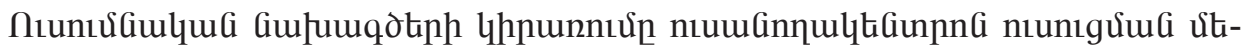

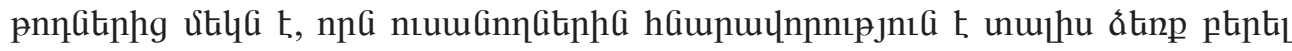

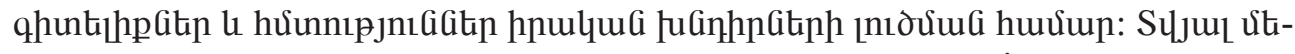

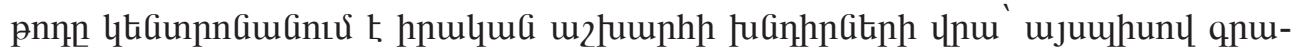

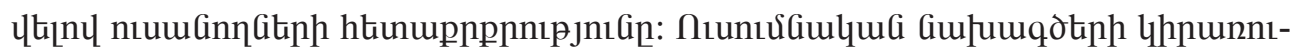

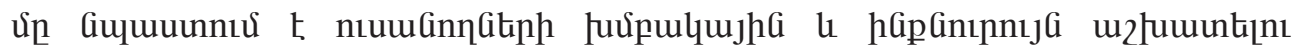
hưunıpjnıGikinh qunqugưuGi: 